\title{
ESTUDO SOBRE AS DIFICULDADES ENCONTRADAS NA UTILIZAÇÃO DOS TERMINAIS RODOVIÁRIOS DA UFPA
}

Olga M. P. Pinheiro1; Elizângela M. R. Gomes²; Larissa A. C. Peniche3; Matheus H. G. Medeiros"; Nathasha E. P. Vilhena5; Alcebíades N. Macêdo ${ }^{6}$.

${ }^{1}$ Graduanda em Engenharia Civil na Universidade Federal do Pará

${ }^{2}$ Graduanda em Engenharia Civil na Universidade Federal do Pará

${ }^{3}$ Graduanda em Engenharia Civil na Universidade Federal do Pará

${ }^{4}$ Graduando em Engenharia Civil na Universidade Federal do Pará

5 Graduanda em Engenharia Civil na Universidade Federal do Pará 6 Professor/Tutor do PET de Engenharia Civil da Universidade Federal do Pará

\section{PET Civil, Universidade Federal do Pará, Belém, Pará.}

Palavras-chave: Transporte público; Ônibus; Infraestrutura; Organização.

\section{Introdução}

A Universidade Federal do Pará dispõe de dois terminais rodoviários (um ao lado do outro, no portão 3 da universidade) responsáveis por atender as demandas tanto dos seus frequentadores quanto da comunidade local. Essas demandas aumentaram junto com o próprio desenvolvimento da instituição e sua área de influência, que anualmente recebem cada vez mais pessoas. Consequentemente, a demanda de utilização dos terminais de ônibus também aumentou.

Devido a este crescimento, tornou-se necessário aumentar a quantidade de ônibus e de linhas no local, que foram sendo inseridas de maneira desorganizada, gerando uma série de desconfortos à população e à comunidade acadêmica. Ressaltando que o ônibus é o principal meio de transporte público em Belém do Pará, este meio de transporte foi criado com o intuito de facilitar a vida do usuário e não o contrário. 
Os objetivos desse trabalho são analisar e expor as principais dificuldades dos usuários do transporte público em Belém do Pará, bem como gerar discussões acerca de possíveis soluções para tais problemáticas.

\section{Metodologia}

Primeiramente, foi elaborado um questionário online, divulgado nas redes sociais, para avaliar o nível de satisfação e possíveis dificuldades enfrentadas pelos usuários de ônibus do terminal rodoviário da Universidade Federal do Pará. No formulário foram utilizadas perguntas voltadas à utilização do local, tais como a avaliação do processo de embarque e desembarque e do acesso dos seus respectivos horários.

Figuras 1, 2 e 3: Questionário "Avaliação do Terminal Rodoviário da UFPA".
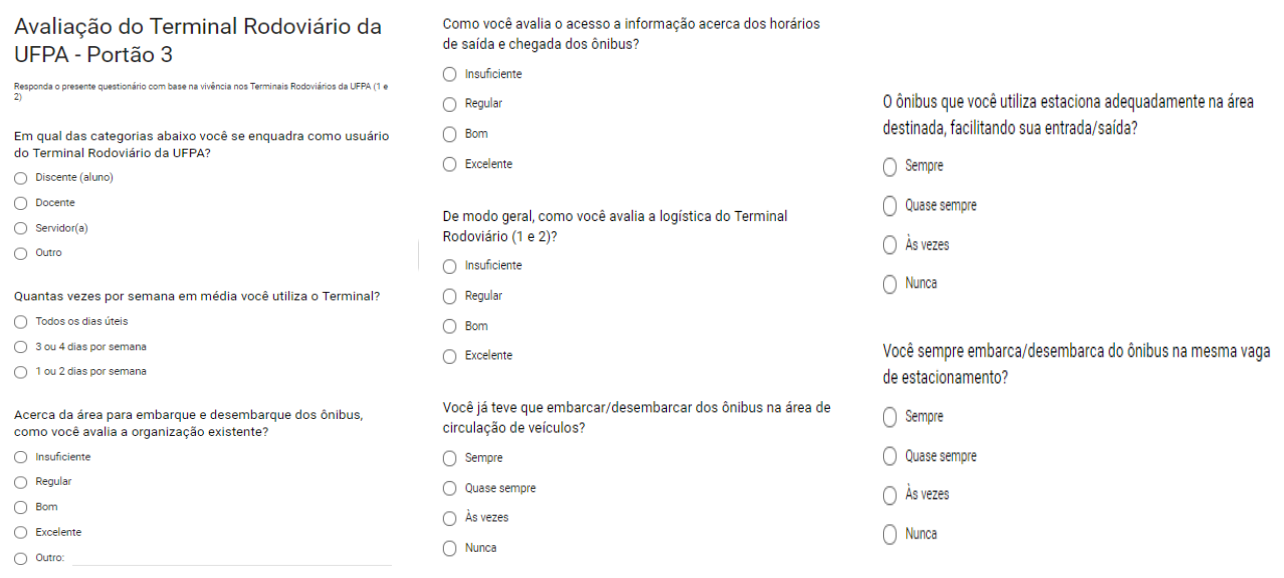

Fonte: Elaborado pelo autor.

Foram registradas as formas de utilização das baias para ônibus e das áreas de embarque e desembarque, a fim de ratificar as respostas coletadas pelo formulário e as observações feitas pelo grupo, em relação às dificuldades que os usuários enfrentam.

O grupo dirigiu-se aos guichês existentes no terminal de ônibus da Universidade Federal do Pará e à garagem da empresa Transurb, localizada em Av. Perimetral, 173 - Terra Firme, Belém - PA, para determinar o número de veículos de cada empresa, as linhas e os horários de saída do terminal, assim como informações adicionais sobre o processo de estacionamento e distribuição dos ônibus no local. No entanto, não foi possível estimar a quantidade de carros da 
linha Pratinha - UFPA, pertencente à empresa transporte Nova Marambaia, pois esta linha não tem como origem o terminal, porém transita no local para embarque e desembarque passageiros, tornando-se, assim, imprescindível levála em consideração para o presente estudo.

Além disso, utilizou-se o Aplicativo Moovit, para aferir o tempo de viagem médio das linhas ônibus.

\section{Resultados e discussão}

Com o formulário online, foi demonstrada a predominância dos estudantes como usuários do local, constituindo $98,16 \%$ de 163 entrevistados. Já em relação à logística geral do terminal e à organização dos locais de embarque e desembarque, foi aferido um nível elevado de insatisfação, devido a não utilização adequada das baias, possuindo $55,83 \%$ de má avaliação. Quanto à insuficiência nas informações sobre horários de saída e chegada disponibilizada para os usuários, afirmada por $76,69 \%$ dos entrevistados, podemos conectá-la à dificuldade dos passageiros em localizar precisamente o seu ônibus, causando desconforto e pequenos tumultos no processo de embarque.

Gráficos 1 a 8 - Produzidos a partir das respostas do formulário online.

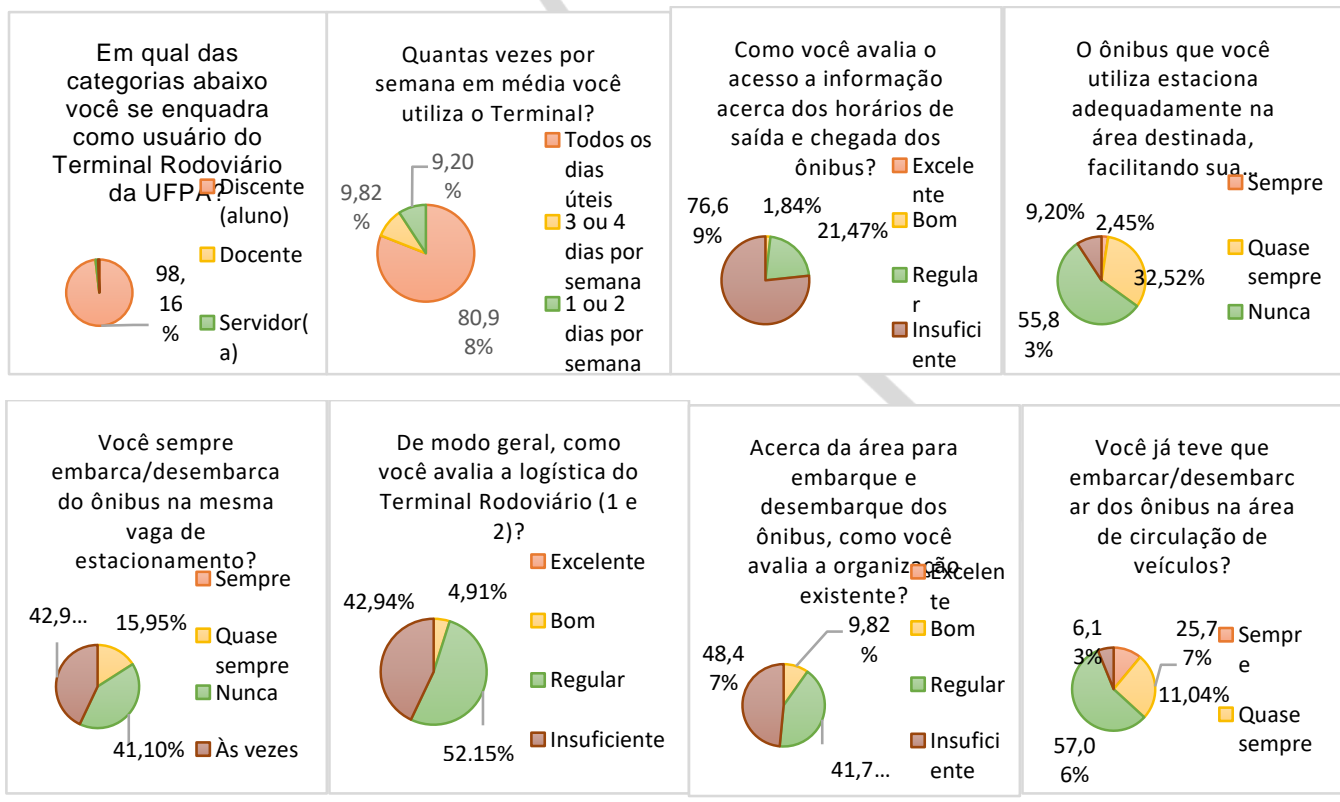

Fonte: Elaborado pelo autor.

O levantamento fotográfico ratificou as dificuldades no processo de embarque, apontando o uso indevido das baias por veículos particulares como um dos 
causadores do problema, como demonstrado nas imagens a seguir. Esta prática ocasiona dificuldades de acessibilidade e também na segurança dos usuários que precisam se deslocar até o meio da pista da garagem para embarcar/desembarcar.

Figuras 4 e 5: Fotos da área de embarque e desembarque do Terminal 1 da UFPA.

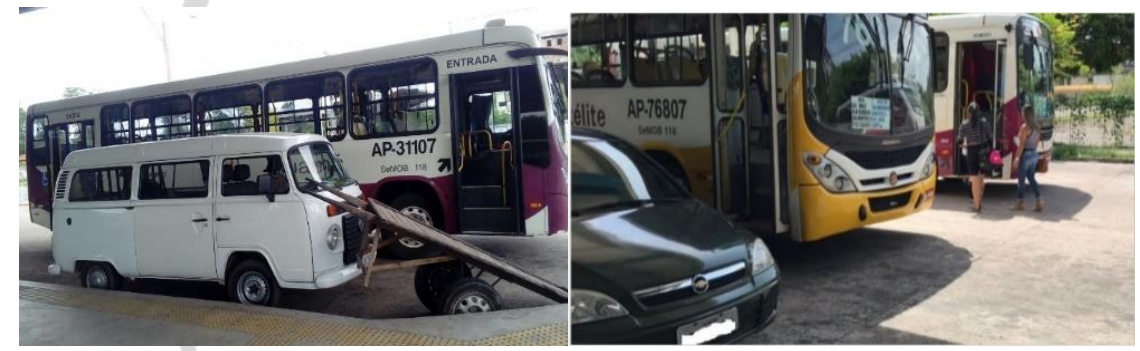

Fonte: Registrado pelo autor, 2018.

Além disso, com a coleta de dados, foi possível identificar as empresas com maior quantidade de veículos e suas frequências de saída. Em relação à organização do terminal, atualmente, os veículos estacionam o mais próximo possível do fiscal de suas empresas e permanecem no local por tempo determinado pelo fiscal, impedindo a utilização de outro veículo para embarque ou desembarque. Seguem os dados obtidos pela equipe.

Tabelas 1 e 2 - Dados da frota de ônibus utilitária do terminal rodoviário 1 e 2 da UFPA.

\begin{tabular}{|c|c|c|c|c|c|c|c|c|c|c|c|}
\hline \multicolumn{6}{|c|}{ Terminal 1} & \multicolumn{6}{|c|}{ Terminal 2} \\
\hline Empresa & Linha & № & 10 Horário de saída & Tempo de viagem & Qtde de Carros & & \multirow{2}{*}{ Linha } & \multirow{2}{*}{ № } & \multirow{2}{*}{$\begin{array}{c}\text { 10 Horário de } \\
\text { sáída }\end{array}$} & \multirow{2}{*}{$\begin{array}{c}\text { estimativa da } \\
\text { viagem }\end{array}$} & \multirow{2}{*}{$\begin{array}{l}\text { Qtde de } \\
\text { Carros }\end{array}$} \\
\hline \multirow{7}{*}{$\begin{array}{l}\text { Viação } \\
\text { Guajará }\end{array}$} & Cremação - Estrada Nova & 113 & 05:10 & 01:05 & 10 & Empresa & & & & & \\
\hline & Cremação - Alcindo Cacela & 114 & 05:10 & 02:00 & 14 & \multirow{3}{*}{ Transurb } & UFPA-lcoaraci & 305 & $06: 30$ & $02: 50$ & 2 \\
\hline & UFPA- Pedreira & 306 & 05:00 & 01:25 & 16 & & UFPA-Tamoios & 320 & 04:00 & 01:20 & 16 \\
\hline & UFPA- Padre Eutiquio & 307 & 05:00 & 02:00 & 13 & & UFPA-Cidade Nova 6 & 321 & 06:10 & 02:30 & 10 \\
\hline & $\begin{array}{l}\text { UFPA - Alcindo Cacela } \\
\text { UFPA - Ver-o-Peso }\end{array}$ & 308 & 05:10 & $02: 00$ & 10 & Transporte Nova & & & & & \\
\hline & $\begin{array}{c}\text { UFPA - Ver-o-Peso } \\
\text { UFPA - Presidente Vargas }\end{array}$ & $\begin{array}{l}309 \\
310\end{array}$ & 05:10 & 01:05 & $\frac{10}{5}$ & Marambaia & Pratinha -UFPA & 643 & $06: 18$ & $02: 50$ & \\
\hline & UFPA - Centro Histórico & 315 & 05:00 & 01:00 & 7 & & Tapanâ-UfPA & 860 & 05:10 & 02:20 & 4 \\
\hline & $\begin{array}{c}\text { UFPA - Marituba } \\
\text { Guamá - Conselheiro }\end{array}$ & $\begin{array}{l}914 \\
311\end{array}$ & $\begin{array}{l}06: 05 \\
05: 00\end{array}$ & $\begin{array}{l}02: 10 \\
01 \cdot 20\end{array}$ & $\begin{array}{c}5 \\
12\end{array}$ & Viaçāo Guajará & Cidade Nova & 321 & $05: 00$ & $02: 30$ & 10 \\
\hline & Guamá - Montepio & 311 & $05: 00$ & $02: 00$ & 12 & & Icoaraci & 305 & $04: 30$ & $02: 50$ & 4 \\
\hline Rio Guamá & Guamá - Presidente Vargas & 316 & 05:20 & 02:00 & 17 & Viação forte & Curuçamba-UFPA & 999 & $06: 12$ & 02:40 & \\
\hline & Guamá - Pátio Belém & 317 & 05:00 & 01:20 & 8 & Transporte Canadá & UFPA-Alcindo Cacela-José malcher & 417 & $05: 30$ & 02:20 & 18 \\
\hline & UFPA - Satélite & 768 & $05: 00$ & $01: 50$ & 14 & & & & & & \\
\hline Vialoc & UFPA - Marituba & 914 & 06:05 & 02:10 & 5 & Rio Guamá & Icoaraci & 305 & $05: 40$ & $02: 40$ & 4 \\
\hline
\end{tabular}

Fonte: Elaborado pelo autor.

De acordo com os resultados obtidos, foram definidas possíveis ações para otimização do terminal. Foi proposta a divisão e a sinalização do terminal para a definição das áreas de embarque e desembarque; a enumeração das baias, 
reservando o uso delas somente para o transporte coletivo; a criação de setores para empresas específicas, dimensionados de acordo com a demanda de cada empresa (quantidade e frequência de saída de seus veículos).

Figuras 6 e 7: Croquis iniciais da proposta de reorganização dos terminais 1 e 2, respectivamente.
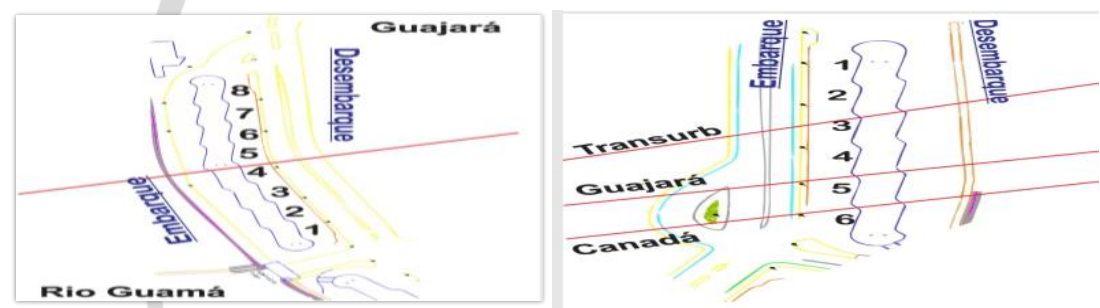

Fonte: Elaborado pelo autor.

Figuras 8 e 9: Imagens da proposta de identificação das baias e das áreas de embarque e desembarque editadas no computador.

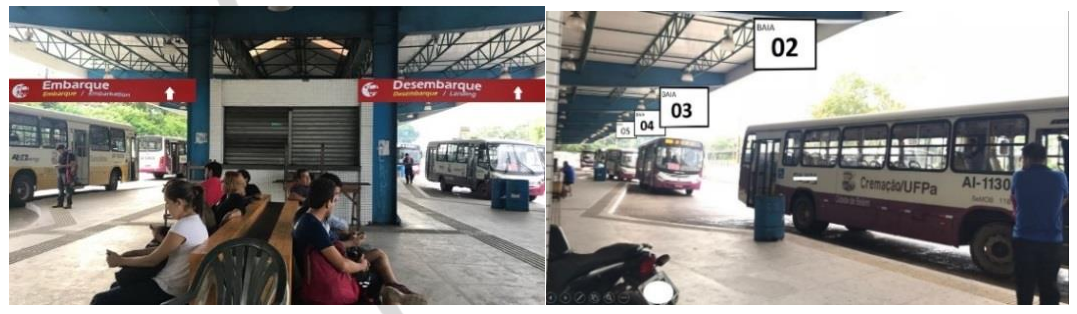

Fonte: Registrado pelo autor, 2018.

Para amenizar a dificuldade de acesso à informação dos usuários em relação ao horário de saída dos ônibus e ao local de embarque, foi proposta a adesão de painéis eletrônicos, alimentados diretamente pelos funcionários dos guichês do terminal rodoviário em tempo real. Assim, os usuários terão ciência dos horários de embarque e aguardarão no local correto.

Tabela 3 - Modelo de distribuição de informações no painel eletrônico.

\begin{tabular}{ccccc}
\hline Ônibus & Empresa & Número & Horário de saída & Baia de embarque \\
\hline UFPA Centro Histórico & Viação Guajará & 315 & $18: 10$ & 05 \\
Guamá Presidente Vargas & Rio Guamá & 316 & $19: 00$ & 03 \\
\hline
\end{tabular}

Fonte: Elaborado pelo autor.

Além disso, se faz necessária uma maior conscientização dos motoristas e usuários do local, principalmente relacionado ao estacionamento indevido nas 
baias destinadas aos ônibus, por meio da sinalização que proíbe o uso inadequado das vagas.

\section{Conclusões}

Através desta pesquisa, foi possível concluir que os principais problemas enfrentados pelos usuários estão relacionados às dificuldades nos processos de embarque e desembarque, causados pela falta de informações de horário e a má utilização do terminal, que vai desde a dinâmica adotada pelas empresas para estacionamento de seus veículos, até o uso indevido das áreas destinadas ao transporte coletivo por veículos particulares.

Tais problemas podem ser amenizados com medidas que envolvem a colaboração das empresas, com a adoção de meios para melhorar a comunicação com seus clientes, assim como modificações em sua rotina de trabalho, no que concerne à utilização das baias de forma adequada. Além disso, se faz necessário uma reorganização no local, envolvendo novas sinalizações e divisões de áreas de acordo com suas funções e linhas de ônibus.

\section{Referências}

ASSOCIAÇÃO BRASILEIRA DE NORMAS TÉCNICAS - ABNT. NBR 14022 Acessibilidade em veículos de características urbanas para o transporte coletivo de passageiros. Rio de Janeiro, 2011.

BELÉM. Lei n. 8.655, de 30 de julho de 2008. Plano Diretor de Belém. Prefeitura Municipal de Belém.

Professor Gorrone Reck. Departamento de Transporte. UFPR. 2006 (Apostila de transporte público)

Ministério das Cidades. WRI Brasil. ANPTrilhos (Brasil). Caderno técnico para projeto de mobilidade urbana - Sistema de prioridades ao ônibus, 2016. 